\title{
UMA ANÁLISE DE ARTIGOS SOBRE RESILIÊNCIA A PARTIR DE UMA LEITURA KLEINIANA
}

\author{
Selma Aparecida Geraldo Benzoni* \\ Cassia Regina Rodrigues Varga"
}

\begin{abstract}
RESUMO. Com o objetivo de compreender os mecanismos inconscientes que operam na resiliência, possibilitando que os indivíduos superem as adversidades e nestas encontrem formas criativas de superação, este artigo analisa a produção científica que utilizou pesquisas encontradas nas bases de dados LILACS, MEDLINE, ADOLEC, BDENF, PAHO e Index Psi no período de 1997 até 2007 que versassem sobre os mecanismos psíquicos que favorecem o processo de resiliência. A análise dos artigos foi realizada pela técnica de análise de conteúdo temática à luz dos pressupostos kleinianos. Encontramos nessa análise duas categorias temáticas: "Sentidos da reelaboração da dor ou de uma ferida", a qual expressou a capacidade de integração dos elementos amorosos e destrutivos, e "Acreditar em si e no outro como alicerce do processo de identificação em que se percebe parte de si no outro". Podemos conjecturar, pelos depoimentos descritos nos artigos de pessoas consideradas resilientes, que os dois processos ocorrem e que cada um mostra mecanismos diferentes.
\end{abstract}

Palavras-chave: Resiliência; elaboração psíquica; objeto bom e mau; introjeção e projeção.

\section{AN ANALYSIS OF ARTICLES ON RESILIENCY FROM A KLEINIANA READING}

\begin{abstract}
This article objective is to understand the unconscious mechanisms that operate in resilience enabling individuals to overcome adversity, finding these, creative ways to overcome them. This article aims to analyze the scientific productions carried out through research with humans, which deals with the psychological mechanisms that favor the process of resilience in the databases LILACS, MEDLINE, ADOLEC, BDENF, PAHO and Index Psi from 1997 until 2007. The analysis of the article was performed using the technique of thematic content analysis in the light of Kleinian's assumptions. Through this technique, we found two categories: reworking of the sense of pain or a wound, that showed integration capabilities of the loving and destructive elements and, believes in themselves and in others as a foundation in the process of identifying what is perceived in the other part of you. We can conjecture through the testimony described in the articles of people considered resilient that the two processes occur, each of which demonstrates different mechanisms in their occurrence.
\end{abstract}

Key words: Resilience, psychic development, good and bad object, introjection and projection.

\section{UN ANÁLISIS DE LOS ARTÍCULOS DE RESILIENCIA DE UNA LECTURA DE KLEINIANA}

RESUMEN. Con el objetivo de comprender los mecanismos inconscientes que actúan en la resiliencia posibilitando que las personas superen las adversidades, encontrando en estas, formas creativas de superación. Este artículo tuve como objetivo, analizar la producción científica hecha a través de investigación con seres humanos, que se ocupan de los mecanismos psicológicos que facilitan el proceso de resiliencia, en las bases de datos LILACS, MEDLINE, ADOLEC, BDENF, PAHO e Index Psi en el período de 1997 hasta 2007. El análisis de los artículos fue hecho con la técnica de análisis del contenido temático a la luz de los presupuestos kleinianos. A través de esta técnica, encontramos dos categorías: sentidos de reelaboración de dolor o de una herida, que esperezó la capacidad de integración de los elementos amorosos y destructivos y, creyeron en sí mismos, el otro como fundación del proceso de identificación en que se percibe parte de si en el otro. Podemos conjeturar, a través de los testimonios descritos en los artículos, de personas consideradas resilientes, que los dos procesos ocurren, siendo que cada un presenta distintos mecanismos para su ocurrencia.

Palabras-clave: Resiliencia, el desarrollo psíquico, objeto bueno y malo, introyección y proyección.

Mestrado em Área de Concentração - Saúde Mental pela Fac. de Medicina de Ribeirão Preto - Universidade de São Paulo, Brasil (1998). Professor Adjunto I da Universidade Paulista, Brasil.

II Doutorado em Medicina (Saúde Mental) pela Universidade de São Paulo, Brasil (2001). Professor Adjunto da Universidade Federal de São Carlos, Brasil. 
Resiliência tem sido um tema muito pesquisado nos últimas décadas por profissionais da Psicologia, da Sociologia e da Psicanálise (Cyrulnik, 2004; Laranjeira, 2007; Silva, Lunardi, Lunardi Filho \& Tavares, 2005; Haudenschild et al., 2005; Cremasco, 2008; Czemy, 2007; Junqueira \& Deslandes, 2003; Yunes, 2003; Pinheiro, 2004 e outros). Este tema tem despertado muito interesse entre os profissionais de saúde, pois auxilia na compreensão dos processos utilizados pelos seres humanos para superar situações adversas e os estudos dos mecanismos utilizados por estes indivíduos contribuem para que os profissionais de saúde mental possam refletir sobre sua prática e buscar, a partir desta, possíveis manejos que maximizam o processo resiliente em seus pacientes, assim como nas instituições.

O termo resiliência foi primeiramente utilizado na Física, para definir a capacidade de um material atingir sua deformação máxima sem sofrer alterações permanentes e com a capacidade de voltar ao seu estado originário (Yune, 2003). No dicionário Aurélio, resiliência é definida como: "propriedade pela qual a energia armazenada em um corpo deformado é devolvida quando cessa a tensão causadora de uma deformação elástica" (Ferreira, 1988, p. 566). Nas ciências humanas a resiliência é a capacidade das pessoas de não só sobreviver às adversidades, mas também de conseguir, a partir da adversidade, tirar proveito e se desenvolver, isto é, de mostrar a capacidade de construir-se e reconstruir-se a partir da adversidade. Silva et al. (2005) definem esse termo como a capacidade dos seres humanos de enfrentar e responder de forma positiva às experiências que possuem elevado potencial de risco para sua saúde e desenvolvimento. Laranjeira (2007) definiu resiliência como a adaptação em face do perigo, ou a capacidade de sair vencedor de uma situação que poderia ter sido traumática.

O processo criativo pode ser uma das possibilidades para se sair vencedor de uma situação traumática, já que este processo é definido como a capacidade de criar alternativas vitais, o que está em consonância com a definição de resiliência como "uma capacidade humana de fazer frente às adversidades da vida, ou mesmo transformá-las, criando novas alternativas vitais" (Haudenschild et al., 2005, online).

As definições encontradas sobre resiliência estão constantemente vinculadas à capacidade de transformar a adversidade, cabendo, então, pensarmos o que seria esta adversidade. As adversidades podem ser pensadas como eventos catastróficos - por exemplo, guerras, acidentes aéreos, a condição de viver em ambientes violentos e outros; no entanto, quando se fala em adversidade, não se está afirmando que toda situação adversa será um trauma. Trauma é um acontecimento da vida do sujeito que se define pela sua intensidade, pela incapacidade em que se encontra o sujeito de reagir a ele de forma adequada, pelo transtorno e pelos efeitos patogênicos duradouros que provoca na organização psíquica. Em termos econômicos, o traumatismo caracteriza-se por um afluxo de excitações que é excessivo, relativamente à tolerância do indivíduo e à sua capacidade de dominar e de elaborar psiquicamente estas excitações (Laplanche e Pontalis, 1998, p. 522).

O termo adversidade tem como sinônimos, no dicionário Aurélio (Ferreira, 1988, p. 18) "1. contrariedade, aborrecimento. 2. Infelicidade, infortúnio, revés"; portanto é um termo bastante genérico. Pode combinar-se com fatores externos ao indivíduo, advindos do meio ambiente, que podem ou não ser percebidos como causas de risco à sua saúde mental, ou seja, podem não ser representados como algo adverso.

Segundo Rodriguez (2005), há diferenças individuais na percepção de fatos. Assim, o que pode ser visto como risco para uns, pode não o ser para outros; ou para uma mesma pessoa, uma determinada situação pode mobilizar toda a sua capacidade criativa e de superação dos conflitos e em outra situação isto pode não acontecer. Ao longo da vida, as situações vão se transformando, devido à percepção do mundo mental que vai se modificando à medida que vão ocorrendo as situações cotidianas.

Tendo esta percepção sobre a situação adversa, este artigo enfatizará os aspectos internos utilizados no processo de resiliência, segundo os pressupostos de Melanie Klein.

A percepção da adversidade como fator de risco ou de proteção está relacionada à maneira como representamos a situação adversa; ela pode ou não ser traumática, a depender da maneira como cada indivíduo internaliza os objetos e de sua capacidade de elaborar a situação. Elaborar, para Klein é a capacidade de "vivenciar reiteradamente suas emoções, ansiedade e situações passadas (...) com diferentes pessoas e situações na vida presente e passada do paciente" (Klein, 1991, p. 289).

Para ocorrer o processo de elaboração a pessoa lançará mão de mecanismos como a simbolização, que também se constitui num processo em que uma representação toma o lugar do objeto ou o substitui, sem qualquer mudança de afeto (Segal, 1991). É pelas simbolizações que o indivíduo poderá perceber as noções de diferenças e semelhanças parciais e 
atribuições de significado dados aos objetos (Klein, 1991), o que lhe permite postergar as satisfações imediatas e reelaborar sua percepção da situação adversa, ou simbolizá-la de forma diferente.

Para Klein (1991), quando uma dor é tão grande que não se pode suportar, o ser humano utiliza mecanismos intrapsíquicos que lhe torna possível suportar esta dor. Os mecanismos mais primitivos que o ser humano utiliza são a projeção, a introjeção e a cisão, as quais, apesar de serem elementos primitivos, continuam a ser utilizadas ao longo da vida. Desde o princípio da vida o ser humano, para Freud, apresenta duas pulsões: a de vida (Eros), que é uma pulsão de sobrevivência, e a de morte (Tanathos), voltada para a destruição; porém no artigo "Além do princípio do prazer", Freud (1920/2006) afirma que a pulsão de morte é também para a sobrevivência e é silenciosa, já que sem a pulsão de morte não poderia ocorrer a busca pela vida.

As pulsões de vida e de morte entram em conflito, e a luta faz que seja ativada uma das principais funções do ego: o domínio da ansiedade. A ansiedade/angústia primordial contra a qual o ego luta é a ameaça que surge da pulsão de morte. Para minimizar esta ansiedade o ego utiliza dois mecanismos: a projeção e a introjeção.

A projeção é uma atividade elementar, inconsciente, que atribui a outras pessoas à sua volta sentimentos de diversos tipos, predominantemente o amor e o ódio. A projeção é um mecanismo utilizado para minimizar e superar angústias/ansiedades com vista a livrar do perigo e da maldade (ansiedade persecutória), e ela o faz situando esses sentimentos em elementos do mundo externo; no entanto, simultaneamente, parte desses impulsos destrutivos é ex-cindida, ou seja, é projetada e cindida, e se associa à libido, permanecendo no indivíduo elementos destrutivos necessários para que ele possa, com esta agressividade, enfrentar os elementos persecutórios. Denomina-se 'elementos persecutórios' tudo que é sentido ou vivenciado como uma agressão à capacidade de pessoa. Se no início da vida o mecanismo de projeção não puder operar, o ser humano correrá o risco de ser inundado por seus impulsos destrutivos, e é desta maneira que o ego é posto em ação pela pulsão de vida. $\mathrm{O}$ processo de projeção é a maneira pela qual é possível defletir a pulsão de morte para o exterior.

$\mathrm{Na}$ introjeção,

(...) o mundo externo, seu impacto, as situações que o bebê atravessa e os objetos que ele encontra não são vivenciados apenas como externos, mas são levados para dentro do self, vindo a fazer a parte de sua vida interior. Essa vida interior (...) não pode ser avaliada sem esses acréscimos à personalidade derivados da introjeção contínua (Klein, 1991, p. 284).

A introjeção também está, em grande medida, a serviço da pulsão de vida; ela combate a pulsão de morte porque leva o ego a receber algo vitalizador (comida, em primeiro lugar), ligando-se por meio desse combate ao trabalho interno da pulsão de morte.

$\mathrm{Na}$ utilização do mecanismo projetivo a pessoa, por meio de fantasias, coloca para fora de si elementos destruídos e também elementos da libido, e introjeta elementos de destruição e de construção. É pelos processos de introjeção e projeção que operam ao longo da vida que ocorre a interação entre o mundo interno e a realidade externa; portanto, "o julgamento da realidade nunca é completamente livre da influência de seu mundo interno", já que a percepção que o indivíduo tem da realidade externa também está na perspectiva dos elementos de seu mundo interno (Klein, 1991, p. 284).

Klein (1991, p. 272) afirma: “(...) a necessidade de dominar a ansiedade persecutória é a força propulsora para cindir o seio e a mãe, externa e internamente, num objeto protetor e amado, por um lado, e num objeto amedrontador e odiado, por outro."

Tendo esta visão de dois objetos, um bom e um mau, Klein (1991) relata que o ser humano no início da vida tem um ego desprovido de coesão e dominado pela cisão.

O perigo de ser destruído pela pulsão de
morte dirigida contra o self contribui para a
cisão dos impulsos em bons e maus, e devido
à projeção desses impulsos sobre o objeto
imaginário, este também é cindido em bom e
mau. Como consequiência, nos estágios mais
iniciais, a parte boa do ego e o objeto bom
estão, em certa medida, protegidos, já que a
agressão é desviada deles. Esses são os
processos específicos de cisão que tenho
descrito como a base de uma segurança
relativa no bebê muito pequeno, na medida
em que é possível alcançar segurança nesse
estágio, ao passo que outros processos de
cisão, como, por exemplo, os que levam à
fragmentação, são prejudiciais ao ego e sua
força (Klein, 1991, p. 341).

A autora relata que existem bebês que não são capazes de sobreviver, pois não foram capazes de desenvolver uma relação confiante com uma mãe bondosa, enquanto outros “(...) passam por grandes dificuldades mas conservam vitalidade suficiente para 
fazer uso da ajuda e do alimento oferecidos pela mãe" (Klein, 1991, p. 287).

O processo de cisão muda em forma e conteúdo à medida que se dá o desenvolvimento, embora nunca seja totalmente abandonado, pois, segundo Klein, há, de algum modo, um predomínio da combinação de impulsos destrutivos onipotentes, ansiedade persecutória e cisão; contudo, com o desenvolvimento há uma crescente integração do ego:

Esse processo de integração baseia-se na introjeção do objeto bom, primordialmente um objeto parcial - seio da mãe, embora outros aspectos da mãe também entrem até na mais antiga relação. Se o objeto interno bom é estabelecido com relativa segurança, ele se torna o cerne do ego em desenvolvimento (Klein, 1991, p. 341).

Não obstante, paradoxalmente, a integração é algo de difícil aceitação, pois gera a ansiedade de que os sentimentos destrutivos possam dominar os sentimentos amorosos e colocar em risco o objeto bom, ocorrendo o conflito ao se alcançar a integração, pois se pode pensar a integração como uma proteção contra os impulsos destrutivos e o medo de que, com a integração, os impulsos destrutivos coloquem em perigo o objeto bom e as partes boas do self.

Com o desenvolvimento do ego, o processo de cisão diminui e há uma maior capacidade de entender a realidade externa e, em alguma medida, de conciliar aspectos bons e maus. "Isso significa que as pessoas podem ser amadas apesar de suas falhas e que o mundo não é visto apenas em termos de preto e branco" (Klein, 1991, p. 289).

O bebê teme pelos estragos que seus impulsos destrutivos e sua voracidade ${ }^{1}$ podem causar ou podem ter causado aos objetos amados.

Klein afirma que as fontes de esperança para a busca constante na integração "derivam da força do ego e da confiança em si mesmo e nos outros" (Klein, 1991, p. 346). Afirma ainda que

a internalização bem-sucedida do objeto bom é a raiz de uma identificação com ele, o que fortalece o sentimento de confiança e daquilo que é bom tanto no objeto como no self.

1 "É uma forma de introjeção executada com raiva. A violência da incorporação oral, envolvendo o morder, conduz, na fantasia, à destruição do objeto. $\mathrm{O}$ estado final fica sendo de que não houve satisfação oral, de vez que o objeto introjetado não tem valor, ou pior que isso, transformou-se em um perseguidor retaliatório, em reação ao ataque sádico oral efetuado no processo de incorporação" (Hinshelwood, 1992, p. 484).
Essa identificação com o objeto bom mitiga os impulsos destrutivos, e, desse modo, diminui também a severidade do superego. Um superego mais ameno faz exigências menos rigorosas ao ego e isso leva à tolerância e à habilidade para aguentar deficiências nos objetos amados, sem prejudicar a relação com eles (Klein, 1991, p. 350).

A identificação é poder reconhecer no outro sentimentos que são próprios, para assim poder compreender o outro e a si mesmo.

A busca da integração está associada à capacidade do indivíduo de suportar sua dor. É necessário que ele acredite em si, que se acredite capaz de lidar com seus impulsos amorosos e destrutivos e de fantasiar sem que a sua fantasia cause uma total destruição ou aniquilamento; e uma das formas de vivenciar suas fantasias, tanto as destrutivas como as amorosas, é poder transformá-las em outros elementos e construir simbolizações.

Klein (1991) define fantasia como:

(...) o corolário mental, o representante psíquico da pulsão. Não há impulso, necessidade ou resposta pulsionais que não sejam vivenciados como fantasia inconsciente ... Uma fantasia representa o conteúdo particular das necessidades ou sentimentos (por exemplo, desejos, medos, ansiedades, triunfos, amor ou tristeza) que dominam a mente no momento (Klein, 1991, p. 285).

A fantasia permite à pessoa vivenciar com seus recursos internos suas necessidades e respostas pulsionais.

Para Milgran e Palti (1993, citados por Haudenschild et al., 2005), as condições de resiliência nascem em função da interação dos processos sociais e intrapsíquicos; são a mola propulsora da condição resiliente à introjeção e identificação com os objetos primários, núcleo em torno do qual se desenvolve o self. Caso a ansiedade despertada pela atividade da pulsão de morte seja sentida como aniquilamento (morte), ao invés da possibilidade de encontrar elementos amorosos para aceitar o alimento e o amor da mãe, isso poderia levar o indivíduo a desenvolver algum tipo de patologia.

Quando uma pessoa vivencia um trauma, não é possível continuar a vida como se não tivesse ocorrido nada, pois negar o trauma é torná-lo algo impensável, impossibilitando a articulação de novas tramas para um drama; ou seja, do ponto de vista mental, 
paradoxalmente, é por meio do trauma que se constitui uma possibilidade de ser reeditada a pulsão de vida e do amor em si e no outro. Uma das vias/armas principais da resiliência é a capacidade de fantasiar, de simbolizar a dor, de utilizar-se de mecanismos, por vezes primitivos, que possam levar a uma nova integração. É preciso haver “(....) uma interação constante entre fatores internos e externos na vida mental, baseada nos processos de projeção e introjeção que dão início às relações de objeto" (Klein, 1991, p. 353).

Montagna (2005) aponta questões e fatores que favorecem a construção de resiliência: sentir-se acompanhado ajuda a sair da solidão, que é uma das características dos elementos traumáticos; aguentar a angústia; utilizar-se dos elementos lúdicos para chegar à simbolização; não isolar-se; estar envolto em atividades comuns; atrair assistência; manter o senso de humor; encontrar sentido no caos.

Destarte, a pessoa que alcança a resiliência pensa seu trauma e o transforma a partir de suas fantasias, como o bebê que alucina o seio materno para dar conta da realidade interna e externa, reelaborando-a através de fantasias, que irão permitir-lhe ser alguém com o poder de produzir e de se doar, inserindo-se na cultura. Em síntese, resiliência é um processo que permite ter consciência de que se pode ser potente, tornando o trauma algo simbolizável e reelaborado; é encontrar a sobrevivência através da pulsão de morte.

Durante este processo de integração (elaboração) pode ocorrer a introjeção em sua etapa final de assimilação que "nos permite conceber objetos internos que se tornam uma parte do ego, realçam-no, e proporcionam habilidades, atitudes, qualidade, constituintes e defesas com que o ego fica subseqüientemente à sua disposição, através da identificação com esse objeto interno" (Hinshelwood, 1992, p. 241).

Para Klein (1996, p 353), ao “(...) agir com outra pessoa como mãe boa ou pai bom, recriamos e aproveitamos na fantasia o amor e a bondade que tanto desejávamos dos pais. Mas agir como pais bons com outras pessoas também pode ser uma maneira de lidar com as frustrações e sofrimentos do passado". E poder fantasiar o que é ideal.

Klein (1996, p. 253) diz ainda:

À medida que o ego se desenvolve, uma relação verdadeira com a realidade vai se estabelecendo a partir dessa realidade irreal. Assim, o desenvolvimento do ego e a relação com a realidade dependem da capacidade do indivíduo de tolerar a pressão das primeiras situações de ansiedade, já num período muito inicial. Como de costume, é preciso um equilíbrio ideal entre os fatores envolvidos. Uma certa quantidade de ansiedade é a base necessária para que e a formação de símbolos e a fantasia ocorram em abundancia; é essencial que o ego possua a capacidade adequada de tolerar a ansiedade, a fim de elaborá-la de forma satisfatória. Desse modo, essa fase básica terá uma conclusão favorável e o desenvolvimento do ego será bemsucedido.

A fantasia irreal de pais muito bondosos pode ser percebida por meio do mecanismo de idealização, que faz a pessoa criar a crença de que podem existir pais muitos amorosos, mesmo na adversidade.

O desenvolvimento mental vai sendo construído com base em duas capacidades: a amorosa, que tem como matéria-prima o impulso de vida, e a egoíca, que permite que o indivíduo vá se reconhecendo realisticamente pelo que é. Esse processo, curiosamente ambíguo, origina os símbolos, que são reconhecidos como detentores de qualidades próprias, mas, ao mesmo tempo, são estruturados como se representassem algum outro objeto com propriedades e atributos inteiramente diferentes. A internalização de símbolos, fruto desse processo, pode ajudar na recriação do objeto interno danificado.

Dada a complexidade deste processo, este trabalho poderá contribuir para que psicoterapeutas compreendam os fatores intrapsíquicos que auxiliam na superação de traumas, o que forneceria subsídios para elaborar e reelaborar estratégias para o manejo clínico.

Para tanto, o presente estudo objetiva analisar a produção científica com seres humanos do período de 1997 até 2007 referentes aos mecanismos inconscientes que favorecem o processo de resiliência, tendo como pressuposto a psicanálise na perspectiva kleiniana.

\section{MÉTODO}

Para atingir o objetivo proposto, realizou-se uma revisão narrativa da literatura. O levantamento bibliográfico contemplou os periódicos indexados nas bases de dados LILACS (Literatura Latino-Americana e do Caribe em Ciências da Saúde), MEDLINE (Literatura Internacional em Ciências da Saúde), ADOLEC (Saúde na adolescência), BDENF (Bases de Dados de Enfermagem), PAHO (Organização Pan Americana de Saúde) e Index Psi, usando o descritor resiliência. Foram adotados os seguintes critérios de inclusão: a) a publicação ter ocorrido entre 1997 e 
2007; b) ser pesquisa de campo; c) universo amostral ser composto somente de seres humanos; d) apresentar dados empíricos na discussão e ou resultados.

Para análise dos dados foi utilizada a técnica de Análise de Conteúdo temática proposta por Minayo (2004, p. 209), “(...) a qual consiste em descobrir os núcleos de sentido que compõem a comunicação, cuja presença signifique alguma coisa com o objetivo analítico visado".

Por meio dessa técnica, após leituras flutuantes dos resultados e/ou da discussão dos dados dos artigos, foram identificadas as unidades de significado, e posteriormente os núcleos de sentidos comuns presentes nos estudos. A partir daí emergiram duas categorias: "Os sentidos da reelaboração da dor ou de uma ferida" e "Acreditar em si e no outro".

\section{RESULTADOS E DISCUSSÃO}

$\mathrm{Na}$ análise dos dados observamos que a maior concentração de artigos ocorre nos anos de 2005 e 2006, com um total de 164 artigos encontrados. A base de dados LILACS foi a que apresentou número maior de artigos (100), seguindo-se o Index Psi, com 33, ADOLEC, com 24, e MEDLINE, com sete.

Em seguida foram excluídos os artigos que apareciam em duas ou mais bases de dados. Para esta análise partiu-se dos dados da LILACS, sendo encontradas: na MEDLINE três citações não duplicados; na Index Psi, 14 citações; e na ADOLEC, duas citações. Nas bases. BDENF e PAHO todos os resultados já haviam aparecido em outras bases de dados. Assim, o total geral de resultados sem repetição foi de 119 citações, das quais 68,1\% apresentam como metodologia a revisão bibliográfica ou meta-análise e apenas 31,9\% são apresentam pesquisa de campo. Destes últimos foram localizados 18 artigos, dos quais dois eram de adaptação de instrumentos para avaliação de resiliência; os demais chegaram a dezesseis artigos.

Desses dezesseis artigos encontrados, apenas oito mostram na discussão dados empíricos que possibilitam a análise dos recursos internos que são utilizados pelos indivíduos resilientes, enquanto os demais falam de vulnerabilidade e fatores de risco e proteção de diferentes grupos. Dos artigos encontrados nas bases de dados nenhum apresenta como fundamentação teórica a Psicanálise.

Para formularmos as categorias levamos em consideração este pensamento de Klein (1996) sobre os primeiros modos de formação dos símbolos, equações simbólicas e identificações que formam o fundamento da relação com o mundo externo, visto que muitos artigos encontrados versavam sobre a questão das adversidades advindas do mundo externo, apesar de os aspectos internos serem pouco explorados.

Para Klein, o mundo interno

(...)pode ser descrito em termos de relações e acontecimentos internos, é o produto dos próprios impulsos, emoções e fantasias do bebê. Sem dúvida, esse mundo é profundamente influenciado pelas boas e más experiências do bebê, provindas de fontes externas. Mas, ao mesmo tempo, o mundo interno influencia sua percepção do mundo externo, de uma maneira não menos decisiva para seu desenvolvimento (Klein, 1991, pp.170-1).

A relação do indivíduo com outras pessoas no mundo externo está associada ao seu mundo interno e estas trocas se dão mediante um processo de projeção e introjeção em que aspectos do indivíduo ficam projetados no outro, e esse indivíduo internaliza aspectos do outro que podem ser por ele percebidos como invasão ou como forma de construir-se.

Pensando nos fatores internos associados à capacidade do indivíduo de continuar a viver, encontramos nos artigos pesquisados a existência de dois processos: a elaboração e a identificação.

\section{Os sentidos da reelaboração da dor ou de uma ferida}

A elaboração está associada à capacidade da pessoa de integrar os elementos destrutivos e os amorosos. Klein diz: "A ansiedade de que os sentimentos hostis destruam os objetos amados diminui quando esses sentimentos tornam-se mais conhecidos e são integrados na personalidade" (Klein, 1991, p. 265). Tendo como base os discursos das pessoas consideradas resilientes nos estudos, pudemos perceber que estas utilizam dois mecanismos no processo de elaboração: a simbolização e a introjeção.

A capacidade egoica de suportar a dor e poder simbolizá-la permite à pessoa reconhecer seus aspectos destrutivos e simbolizá-los de tal forma que possam transformar-se em algo criativo e saudável.

No artigo de Paludo e Koller (2005) uma moradora de rua, adolescente, do sexo feminino diz: “... desde os seis meses eu tô em abrigo, não conheci ninguém da minha família ...” (p. 190), mais adiante ela fala dos seus sentimentos com relação a este abandono:

Eu não sei nada sobre ela, me disseram que o nome dela é Débora. Eu não sei por que ela (mãe) me deixou, entende, eu não vou julgar ela pelo que não sei. Talvez ela teve que 
fazer isso pra alguma coisa, algum negócio. Tenho certeza de que ela achou que estava fazendo o melhor pra mim ... Posso não saber nada, mas tenho certeza de que minha mãe me ama. (Paludo \& Koller, 2005, p. 190).

Podemos conjecturar no depoimento desta adolescente que ela não deixa de considerar a sua dor; ela relata o fato de ter sido abandonada concretamente pela mãe, mas a partir desta sua vivência ela não fica parada ou patologizada.

O mesmo ocorre com uma mulher que foi estuprada, falando do seu estuprador: “(...) eu não consigo ter raiva dele, eu não tenho raiva, eu tenho pena (Violeta)" (Sudário, Almeida \& Jorge, 2005, p. 83)

Klein $(1991,1996)$ diz que quando, na fusão entre a pulsão de vida e a de morte, predomina a pulsão de vida - o que faz supor uma ascendência da capacidade de amar -, o ego é relativamente forte e mais capaz de suportar a ansiedade suscitada pela pulsão de morte e de contrabalançá-la (integração), o que parece ter acontecido com esta adolescente e também parece ser a forma como os indivíduos resilientes suportam suas adversidades sem que com isto deixem de viver.

Uma senhora de 59 anos com diagnóstico de pênfigo vulgar ${ }^{2}$ diz nos seus primeiros dias de internamento: "Eu sou mais que isto (doença), eu sou uma mulher vaidosa, feliz, sempre de bom humor, preciso de vida, preciso também tomar banho, passar perfume. Desde que cheguei aqui não tomo banho" (Bianchini \& Dell'Aglio, 2006, p. 432). Contando sobre sua vida e sua separação conjugal, afirma:

$\mathrm{Na}$ época me senti muito triste, mas a vida tem que continuar e eu tenho muitos amigos no lugar que moro, tenho também amor próprio ... vamos pro bailão da terceira idade quase todos os finais de semana e eu danço sem parar. Adoro dançar e paquerar (Bianchini \& Dell'Aglio, 2006, p. 432).

Podemos ver que a pessoa resiliente sofre com as situações, mas "Sob o impacto da ansiedade, da frustração e de sua insuficiente capacidade de expressar emoções, para com seus objetos amados, ele é levado a transferir suas emoções e ansiedades para

2 "Uma dermatose de etiologia desconhecida, sendo uma autoimune, que gera anticorpos contra uma proteína essencial para adesão das células da pelo. Apresenta-se na forma de lesões cutânea bulbosas, que podem se romper rapidamente, formando ulcerações dolorosas por toda a pele. Se não tratada pode evoluir para um desnudamento intenso, levando a desequilíbrio hidroeletrolítico, sepsis e óbito" (Aoki, citado por Bianchi \& Dell'Aglio, 2006, p. 431). os objetos que o cercam" (Klein, 1991, p. 316). Como expressa o depoimento desta senhora, ao se perceber com uma dor muito grande ela não fica presa em suas incapacidades, mas encontra outros objetos aos quais pode transferir suas ansiedades e assim continuar a vida, integrando seus objetos amados a esta destruição que está sentindo.

Outro fator psíquico utilizado na elaboração é a introjeção, que é utilizada para preservar o ego ou os objetos bons (Klein, 1991).

No artigo de Yunes, Garcia e Albuquerque (2007) sobre a representação de agentes de saúde e educação das famílias monoparentais e a resiliência, os autores apresentam a fala de um dos agentes:

Elas conseguem se alimentar, elas conseguem se vestir. Agora estão até pensando em construir. De vez em quando têm uma dificuldade e outra, mas elas conseguem se virar. E são pessoas assim, pra cima, sabe?! Elas conseguem, vão remando, vão de um jeito, vão de outro e não param, progridem. Viver bem eu acho que entra o lado mental, social, financeiro e tudo (Yunes et al., 2007, p. 448-9).

E ainda neste mesmo artigo:

Três horas da madrugada botei o meu guri em cima de uma carroça e nós fomo para o hospital. Ele numa charrete e pedindo: - não sai correndo com o cavalo, mano, se não eu não aguento de dor - família 2 (Yunes et al., 2007, p. 449).

Hinshelwood (1992) diz que com o tempo a possibilidade de introjetar objetos bons é característica de experiência de um senso interno de bondade ou de autoconfiança e estabilidade mental. Nestes relatos parece acontecer este fato, pois, apesar de viverem em situações tão adversas, essas pessoas conseguem encontrar objetos internos bons que as fazem seguir adiante. $\mathrm{O}$ mecanismo utilizado de introjeção pode ser um recurso para minimizar as ansiedades persecutórias e recuperar o objeto bom excindido.

Isto pode também ser visto no caso de Lúcia, relatado no artigo de Gomes, Rabinovich e Bastos (2005). Uma mulher entrevistada conta sobre os momentos em que sua mãe abandona o marido e os filhos e seu pai passa a maltratar os filhos, negandolhes até mesmo alimentação. Lúcia relata que os vizinhos é que ajudavam as crianças, entre eles, ela própria: "é que ajudavam escondido dele"(p. 53). Apesar destes maus-tratos, ela nunca deixou de frequentar a escola. Aos 19 anos resolveu mudar-se 
para Salvador: “(...) chegou a hora de eu encarar o mundo. Se ficar aqui com meu pai vou morrer" (p. 53). Em que pese a isto, os autores relatam que ela "reconhece e valoriza, contudo o pai por tê-la mandado para a escola, embora não lhe desse nenhum material escolar e a maltratasse constantemente" (p. 54).

Lúcia, embora reconheça as maldades que o pai fazia com ela e seus irmãos, consegue vê-lo como uma figura com aspectos bons e introjeta um pai que pode integrar elementos bons e persecutórios, e pode sentir muito amor por suas filhas: "Não tem nada nesse mundo que eu amo, depois de Deus, mais que vocês" (Gomes et al., 2005, p. 53).

\section{Acreditar em si e no outro}

Klein (1991) diz em seu artigo sobre a identificação:

\begin{abstract}
As relações entre as figuras internalizadas, e entre elas e o ego, tendem a serem vivenciadas, quando a ansiedade persecutória é dominante, como essencialmente hostis e perigosas; são sentidas como sendo amorosas e boas quando o bebê é gratificado e prevalecem sentimentos positivos (Klein, 1991, p. 170).
\end{abstract}

Observamos, nos artigos revisados, que em seu processo de identificação, a pessoa resiliente utiliza-se de dois mecanismos: projeção e a idealização.

Para Klein (1991, p. 224), “os bebês cuja capacidade de amar é forte sentem menos necessidades de idealizar do que aqueles em quem os impulsos destrutivos e a ansiedade persecutória são predominantes".

No artigo sobre o encontro entre moradores de rua e duas professores aposentadas (Alvarez, Alvarenga \& Fiedler-Ferara, 2004) ocorre uma conversa entre Soviético, um dos moradores, e Sílvia, uma das professoras aposentadas, com relação a um desenho feito perto do lugar onde ele dormia:

Por que você desenhou a casa e a igreja? perguntou-lhe Silvia.

Porque esta era a vida que eu queria ter. Minha casa onde eu pudesse ser feliz e com todos vivendo em harmonia ... A igreja era o lugar onde ia me sentir bem e recebendo uma palavra amiga ... (Alvarez et al., 2004, p. 53).

Observamos que Soviético idealiza uma situação em que pudesse ser feliz e suportar a dor de não ter uma casa, uma palavra amiga, e ao ter a professora, pode idealizar a relação com ela também e se perceber como diferente de outros moradores de rua. "Tem uns parceiros que chamam pra roubar e eu não vou roubar ... tô sossegado, quero dar um tempo!“ (p. 53).

No artigo de Alexandre e Vieira (2004), Daniel, um garoto que vive institucionalizado, diz: "A minha mãe vai pedir pro juiz pra ela me levar pra casa com ela. Se ele é bom, ele vai deixar eu ir com minha mãe" (Alexandre \& Vieira, 2004, p. 212), Daniel parece idealizar uma mãe boa e quer tê-la perto de si e poder estar com ela, e não sente a mãe como alguém má. Lucas imagina a possibilidade de estar com uma mãe muito afetuosa, que tem a atitude de se aproximar dos filhos e ajudá-los a crescer e se desenvolver dandolhes recursos para brincar e imaginar. "Quando nós for embora, a mãe vai contá historinha pra mim e pros meus irmãos" (Alexandre e Vieira, 2004, 212). Ele também sonha com a possibilidade de sair da instituição. Estes aspectos de idealização das figuras maternas podem estar a serviço do desenvolvimento do ego, protegendo-o contra as fantasias aterrorizantes. Nesses processos a pulsão de vida aparece novamente e se afirma (Klein, 1991) através da idealização dos aspectos amorosos da figura materna.

Os mesmos aspectos de idealização podem ser observados em um relado do artigo de Poletto, Wagner e Koller (2004) no qual uma garota de 11 anos que tem a responsabilidade de cuidar dos irmãos mais jovens, diz: "Lá em casa nós moramos junto com a minha vó, o meu tio que mora junto e não trabalha e, daí só o meu pai que sustenta e, é difícil pro meu pai e ele tem mais conta" (p. 246). Aqui ela demonstra a idealização do pai como uma figura provedora, que supre as necessidades materiais, no entanto a mãe também contribui para este sustento. Klein afirma que “(...) a idealização deriva do sentimento inato de existir um seio extremamente bom, sentimento que leva ao anseio por um objeto bom e pela capacidade de amá-lo" (1991, p. 224). Parece que no objeto idealizado existe a esperança de ele se tornar o objeto bom que essa pessoa deseja ser.

Outro mecanismo a ser considerado nas pessoas resilientes é que elas, para se identificarem, parecem buscar os aspectos amorosos das outras pessoas e acreditar que existem esses aspectos. Klein (1991) diz: “(...) quando se coloca parte de si mesmo dentro de outra pessoa (projetar), a identificação se baseia na atribuição a essa outra pessoa de algumas das próprias qualidades" (p. 286). É o que ocorre com a adolescente moradora de rua, que diz:

Ah, eu sei lá ... ah não sei como seria se reencontrasse minha mãe. Não sei se poderia 
ser diferente ou não. Eu sei lá, eu levo tudo para o outro lado, assim sabe. Eu gosto das tias de lá. Sabe, Beth, me dou tri bem assim com elas, só que tem umas tias que são tri chatas assim, daí eu pego e largo lá; mas não que eu não goste, me dou tri bem com as tias, só dessa guria (Luciana) sabe que eu tenho nojo. (Paludo \& Koller, 2005, p. 193).

Quando diz sobre as "tias" do abrigo ela parece projetar nestas a possibilidade de ter elementos bons em si que ela identifica nos outros elementos que são seus.

Os pais, em grupo focal para prevenção das drogas, dizem: "Decidi estudiar, para darie ejemplo a mis hijos, los padres debemos ser amigos más que padres y ellos puedem hacer las cosas por rebeldia" (Sànchez \& Ferriani, 2004, p. 356). Os pais projetam no fato de poder dar bons exemplos aos filhos a possibilidade de que estes criem recursos para não se drogarem. É como se, projetando no estudo um aspecto bom deles, eles reconhecessem que o filho também o fará. A projeção parece ser um mecanismo que possibilita à pessoa perceber seus aspectos amorosos em outras e identificar-se com elas.

\section{CONSIDERAÇÕES FINAIS}

Consideramos, neste artigo, a análise dos mecanismos inconscientes utilizados pelas pessoas resilientes em seus processos de sair das situações adversas de forma criativa, podendo continuar seu desenvolvimento.

Observamos que o tema resiliência tem sido muito difundido nas últimas décadas, porém pouquíssimos são os artigos baseados na Psicanálise.

Podemos conjecturar, pelos depoimentos de pessoas consideradas resilientes descritas nos artigos revisados, que ocorrem dois processos: elaboração e identificação, cada um dos quais mostra usar mecanismos diferentes para que o processo ocorra.

A elaboração parece ser um processo mais sofisticado, já que tem em sua essência a capacidade de integração dos elementos amorosos e destrutivos e as pessoas dependem de uma maior capacidade de suportar a dor.

Neste processo os mecanismos utilizados que pudemos observar foram a simbolização e a introjeção. A simbolização é a capacidade de transferir para outro elemento sentimentos e ansiedades que são de um primeiro e podem integrar pulsões de vida e de morte. A introjeção é o mecanismo que possibilita que elementos excindidos sejam assimilados pelo próprio indivíduo, e neste processo, tanto elementos amorosos como destrutivos podem ser suportados e integrados no mundo interno.

No processo de identificação ocorrem mecanismos mais primitivos, que buscam a continuidade do desenvolvimento por meio de mecanismos de idealização e projeção. Na idealização, o que se observou foi que os objetos internos das figuras parentais, especialmente os da mãe, são vistos como figuras idealmente boas, com as quais o sujeito pode se identificar sem que haja conflitos intensos na vivência de aspectos destrutivos; já na projeção, o sujeito atribui às pessoas à sua volta os elementos bons que ele vê em si, podendo se identificar com essas pessoas também pelos seus aspectos positivos. Nesse movimento a pulsão de vida se sobrepõe à pulsão de morte.

Este artigo, embora apresente um referencial específico, possibilita a análise de elementos constituintes do funcionamento mental que parecem contribuir para a reflexão sobre os processos psíquicos que compõem a relação com o profissional da área de saúde mental e sobre seu olhar a respeito dos fenômenos humanos. Os elementos teóricos aqui expostos auxiliam na atuação clínica ou institucional no sentido de que contribuem para uma visão tridimensional dos fenômenos e com isso tornam possível reconhecer os mecanismos que ajudam no desenvolvimento do processo de resiliência.

\section{REFERÊNCIAS}

Alexandre, D. T. \& Vieira, M. L. (2004). Relação de apego entre crianças institucionalizadas que vivem em situação de abrigo. Psicologia em Estudo, 9(2), 207-217.

Alvarez, A. M. S., Alvarenga, A. T. \& Fiedler-Ferrara, N. (2004). O encontro transformador em moradores de rua na cidade de São Paulo. Psicologia \& Sociedade, 16(3), 47-56.

Bianchini, D. C. S. \& Dell'aglio, D. D. (2006). Processo de resiliência no contexto de hospitalização: um estudo de caso. Paidéia, 16 (35), 427-436.

Cremasco, M. V. F. (2008). Violência e resiliência: enfrentamento do traumático na clínica psicanalítica. Latin American Journal of Fundamental PsychoPathology Online, 5(2), 222-240.

Cyrulnik, B. (2004). Os patinhos feios. São Paulo: Martins Fontes.

Czerny, J. (2007). Resenha do livro Falar de amor à beira do abismo. Revista Brasileira de Psicanálise, 41(4), 149-152.

Ferreira, A. B. H. (1988). Novo Dicionário básico de língua portuguesa. Rio de Janeiro: Nova Fronteira; Folha de São Paulo.

Freud, S. (2006). Além do princípio do prazer. In S. Freud. Escritos da psicologia do inconsciente, (L.A. Hans, Coord. Trad.), (pp. 123-182) Rio de Janeiro: Imago. (Original publicado em 1920). 
Gomes, M. C. C., Rabinovich, E. P., \& Bastos, Ana C. de S. (2005). A resiliência em mulheres de um bairro popular de Salvador, Bahia: Recursos pessoais e contextuais. Revista Brasileira de Crescimento e Desenvolvimento Humano, 15(3), 49-56.

Haudenschild, T. R. L (2005). Trauma, resistência e resiliência Congresso da. Associação Internacional de Psicanálise (IPA), 44, Rio de Janeiro. Recuperado em 27 de março, 2008, de http://abp.org.br/teresa_ipa.doc.

Hinshelwood, R. D. (1992). Dicionário do pensamento kleiniano. (J. O. A. Abreu, Trad.). Porto Alegre: Artes Médicas.

Junqueira, M. F. P. S., \& Deslandes, S. F. (2003). Resiliência e maustratos à criança. Cadernos de Saúde Pública, 19 (1), 227-235.

Klein, M. (1991). Inveja e gratidão e outros trabalhos - 1946-1963. (Obras Completas de Melanie Klein, Vol. 3.). (B. H. Mandelbaum et al., Trad.). Rio de Janeiro: Imago.

Klein, M. (1996). Amor, culpa e reparação e outros trabalhos 19211945. (Obras Completas de Melanie Klein, Vol. 1), (A. Cardoso, Trad.). Rio de Janeiro: Imago.

Laplanche, J., \& Pontalis, J. B. (1998). Vocabulário de Psicanálise. (P. Tamen, Trad.), 3a ed. São Paulo: Martins Fontes.

Laranjeira, C. A. S. J. (2007). Do vulnerável ser ao resiliente envelhecer: revisão de literatura. Psicologia teoria e pesquisa, 23(3), 327-332.

Minayo, M. C. S. (2004). O desafio do conhecimento: pesquisa qualitativa em saúde. (Saúde em Debate; 46), 8a ed. São Paulo: Hucitec.

Montagna, P. L. K. (2005) O processo analítico como propiciador de resiliência e a resiliência como balizadora do processo analítico. Congresso da. Associação Internacional de Psicanálise (IPA), 44, Rio de Janeiro. Recuperado em 27 de março, 2008, de http://abp.org.br/teresa_ipa.doc.

Paludo, S. S., \& Koller, S. H. (2005). Resiliência na rua: um estudo de caso. Psicologia: Teoria e Pesquisa, 21 (2), 187-195.
Pinheiro, D. P. N. (2004). A resiliência em discussão. Psicologia em Estudo, 9(1), 67-75.

Poletto, M., Wagner, T. M. C., \& Koller, S. H. (2004). Resiliência e desenvolvimento infantil de crianças que cuidam de crianças: uma visão em perspectiva. Psicologia: Teoria e Pesquisa, 20(3), 241250.

Rodriguéz, D. (2005). El humor como indicador de resiliência. In A. Melillo, E. Ojeda, \& D, Rodriguez. Resiliência: descobriendolas próprias fortalezas. Buenos Aires: Paidos.

Sánches, F. M., \& Ferrieni, M. G. C. (2004). Percepción de padres y profesores de los factores de riesgo para el uso de drogas lícitas e ilícitas em los escolares. Revista Latino-americana de Enfermagem, 12 (especial), 352-358.

Segal, H (1991). Notas sobre a formação de símbolos. In M. Klein. Desenvolvimento da teoria e da técnica. (pp. 167-184). (B. H. Mandelbaum, Trad.). Rio de Janeiro: Imago.

Silva, M. R. S., Lunardi, V. L., Lunardi Filho, W. D., \& Tavares, K. O. (2005). Resiliência e promoção da saúde. Texto \& contexto enfermagem, 14 (especial), 95-102.

Sudário, S., Almeida, P. C., \& Jorge, M. S. B. (2005). Mulheres vítimas de estupro: contexto e enfrentamento dessa realidade. Psicologia \& Sociedade, 17(3), 73-79.

Yunes, M. A. M. (2003). Psicologia positiva e resiliência: o foco no indivíduo e na família. Psicologia e estudos, 8 (especial),75-84.

Yunes, M. A. M., Garcia, N. M., \& Albuquerque, B. M. (2007). Monoparentalidade, pobreza e resiliência: entre as crenças dos profissionais e as possibilidades da convivência familiar. Psicologia: Reflexão e crítica, 20(3), 444-453.

Recebido em 22/11/2009 Aceito em 01/09/2011
Endereço para correspondência:
Selma Aparecida Geraldo Benzoni. Av. Pindorama, 870 - Jd. Aeroporto, CEP: 15991-215, Matão-SP, Brasil. E-mail: selmagbenzoni@uol.com.br. 